\title{
Successful Implementation of a Rapid Response System in the Department of Internal Medicine
}

Yeon Joo Lee, M.D., Jin Joo Park, M.D., Yeonyee E. Yoon, Jin Won Kim, M.D., Jong Sun Park, M.D., Taeyun Kim, M.D.*, Jae Hyuk Lee, M.D. , Jung-Won Suh, M.D., You Hwan Jo, M.D. , Sangheon Park, M.D. ${ }^{\dagger}$, Kyuseok Kim, M.D.*, and Young-Jae Cho, M.D.

Departments of Internal Medicine, ${ }^{*}$ Emergency Medicine, and ${ }^{\dagger}$ Anesthesiology, Seoul National University Bundang Hospital, Seoul National University College of Medicine, Seongnam, Korea

Background: A rapid response system (RRS) aims to prevent unexpected patient death due to clinical errors and is becoming an essential part of intensive care. We examined the activity and outcomes of RRS for patients admitted to our institution's department of internal medicine.

Methods: We retrospectively reviewed patients detected by the RRS and admitted to the medical intensive care unit (MICU) from October 2012 through August 2013. We studied the overall activity of the RRS and compared patient outcomes between those admitted via the RRS and those admitted conventionally.

Results: A total of 4,849 alert lists were generated from 2,505 medical service patients. The RRS was activated in 58 patients: A (Admit to ICU), B (Borderline intervention), C (Consultation), and D (Do not resuscitate) in 26 (44.8\%), 21 (36.2\%), 4 (6.9\%), and 7 (12.1\%) patients, respectively. Low oxygen saturation was the most common criterion for RRS activation. MICU admission via the RRS resulted in a shorter ICU stay than that via conventional admission (6.2 vs. 9.9 days, $p=0.018$ ).

Conclusions: An RRS can be successfully implemented in medical services. ICU admission via the RRS resulted in a shorter ICU stay than that via conventional admission. Further study is required to determine long-term outcomes.

Key Words: intensive care unit; internal medicine; rapid response team.

\section{INTRODUCTION}

Preventing unexpected patient deaths due to clinical errors is an important priority for healthcare systems. A rapid response system (RRS) is one strategy for reducing preventable hospital deaths. As hospitalized patients may exhibit warning signs prior to deterioration, [1,2] RRS have the potential to prevent adverse clinical outcomes including cardiac arrest and death.

Received on December 30, 2013 Revised on April 14, 2014

Accepted on April 22, 2014

Correspondence to: Young-Jae Cho, Department of Internal Medicine,

Seoul National University Bundang Hospital, Seoul National

University College of Medicine, 82 Gumi-ro 173beon-gil, Bundang-gu,

Seongnam 463-707, Korea

Tel: +82-31-787-7058, Fax: +82-31-787-4050

E-mail: lungdrcho@gmail.com
Interest in improving hospital quality and outcomes has prompted the increasing utilization of RRS worldwide.[3] In fact, the Institute for Healthcare Improvement's 100,000 Lives Campaign recommends that hospitals implement RRS as 1 of 6 strategies to reduce preventable in-hospital deaths.[4,5]

Cardiopulmonary arrests and emergency admissions to intensive care units (ICUs) from general wards are often preceded by a prolonged, detectable period of physiological deterioration.[1,6] Furthermore, suboptimal care and delays in general wards before admission to the ICU negatively affect mortality, and patients admitted from general wards have poorer outcomes than those admitted from the operating or emergency room; moreover, longer stay in a hospital ward before ICU admission is an independent predictor of mortality.[6-9] Therefore, it is important to select a proper activation method and criteria tailored to each hospital to successfully operate an RRS.

cc This is an Open Access article distributed under the terms of the Creative Commons Attribution Non-Commercial License (http://creativecommons.org/ licenses/by-nc/3.0/) which permits unrestricted non-commercial use, distribution, and reproduction in any medium, provided the original work is properly cited.

(c) 2014 Korean Society of Critical Care Medicine 
The RRS in our hospital was launched in December 2010 and is based on electronic medical record (EMR) screening with predefined criteria for surgical services and hemato-oncology wards. The RRS has been extended gradually and now covers all patients admitted to hospital wards. The present study assessed the activity of the RRS for patients in the department of internal medicine and examined the particular characteristics and outcomes of patients admitted to the medical ICU (MICU) via the RRS compared to patients admitted conventionally.

\section{MATERIALS AND METHODS}

\section{1) Participants}

This study was conducted at Bundang Seoul National University Hospital, a 1300-bed tertiary care academic hospital affiliated with Seoul National University. Patients deteriorating in general wards detected by RRS monitoring and all patients admitted to the MICU from October 2012 to August 2013 were included. Only patients in medical service wards were included.

We retrospectively reviewed the medical records including the following clinical variables: age, sex, ward of admission, modified early warning score (MEWS), Acute Physiology and Chronic Health Evaluation (APACHE)-II score, Sequential Organ Failure Assessment (SOFA) score, reason for ICU admission, RRS activation criteria, RRS intervention, and survival.

Data collection was approved by the Institutional Review Board of Bundang Seoul National University (IRB No: L-2013-1232), and the study was therefore performed in accordance with the Declaration of Helsinki.

\section{2) Activity and RRS operation}

Bundang Seoul National University Hospital has had an RRS operating since October 2012. This RRS runs throughout the screening system and is based on EMRs; there are 10 activation criteria including 9 kinds of screening criteria and 1 direct call for emergency situations (Table 1).
The 16-bed medical ICU admits approximately 250 patients annually and is managed as a semi-closed unit by board-certified critical care physicians. The RRS is operated through a dashboard monitoring system based on EMRs. If the EMR meets 1 of the 9 screening criteria, the detected abnormal value and patient ID pops up as an alert listed on the dashboard monitor (Fig. 1). Charge RRS nurses with more than 5 years of ICU experience perform primary checks and then call doctors for specific interventions. Activation of the RRS means doctors (i.e., intensivists or fellows) check for alert-listed patients. Admission to the ICU via the RRS is primarily mediated by intensivists. This monitoring system is operated daily from 7 AM to $10 \mathrm{PM}$.

On the other hand, conventional ICU admission is mediated by an on-call ICU resident. If the resident receives calls from wards for deteriorating patients, the resident physician performs a primary check and decides whether to admit the patient to the ICU.

The activity and intervention performed by our RRS are triaged according to the $\mathrm{A} / \mathrm{B} / \mathrm{C}$ triage categories used by critical care response teams in Ontario.[10] This system categorizes patients into the following 3 categories: A (Admit to ICU) are patients admitted to the ICU; B (Borderline) are patients who re-

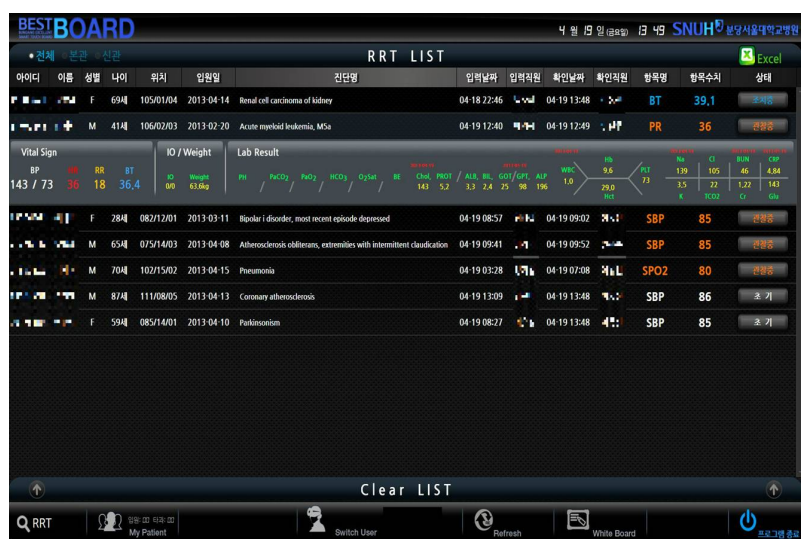

Fig. 1. Dashboard system based on electronic medical records.

Table 1. Activation criteria for the rapid response system

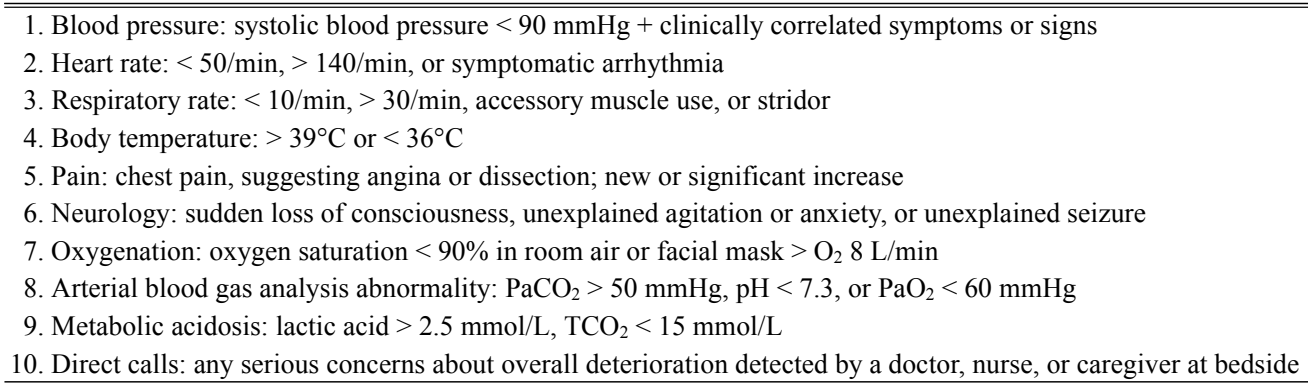




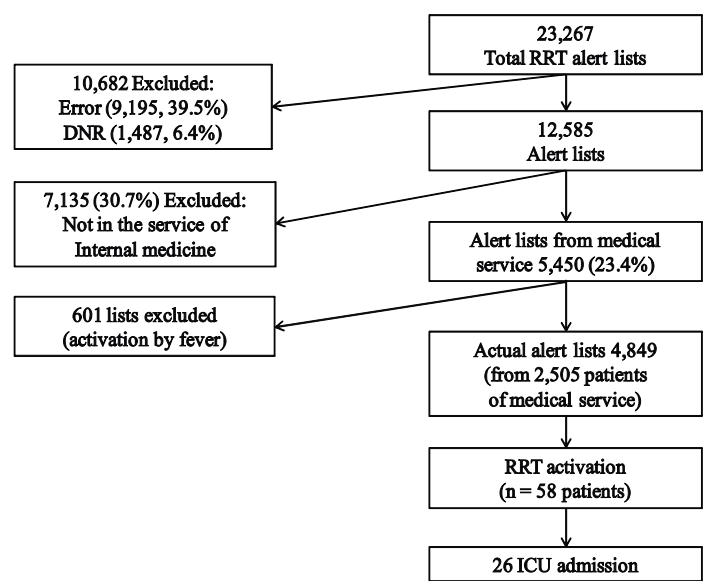

$(2.3 \%)$

Fig. 2. Flowchart of rapid response system activation. quire further assessment, typically investigations or monitoring of response to therapy, to determine their appropriate disposition; and C (Consultation only) are patients who require assessment and recommendations that can be carried out while remaining in their current location. In addition, we added a category D (Do not resuscitate [DNR]), who are patients whose DNR orders are initiated by the RRS team on the wards.

\section{3) Statistical analysis}

Categorical and continuous variables are expressed as numbers and percentages, and means and standard deviations, respectively. Differences between ICU admission via the RRS and conventional method were tested by the independent sam-

Table 2. Clinical characteristics of patients and interventions undertaken with the rapid response system activation

\begin{tabular}{|c|c|}
\hline Characteristic & Values \\
\hline Rapid response system activations, $\mathrm{n}(\%)$ & $58(2.3)$ \\
\hline Age $(y)$, mean \pm SD & $67.1 \pm 11.8$ \\
\hline Male sex, n (\%) & $36(60)$ \\
\hline \multicolumn{2}{|l|}{ Activation methods, $\mathrm{n}(\%)$} \\
\hline Screening & $46(79)$ \\
\hline Call & $9(16)$ \\
\hline Others & $3(5)$ \\
\hline \multicolumn{2}{|l|}{ Wards, n (\%) } \\
\hline Hemato-oncology & $29(48.3)$ \\
\hline Pulmonology & $13(21.7)$ \\
\hline Gastroenterology & $6(10.0)$ \\
\hline Geriatric medicine & $5(8.3)$ \\
\hline Nephrology & $4(6.7)$ \\
\hline Cardiology & $1(1.7)$ \\
\hline Response time ( $\mathrm{min}$ ), mean $\pm \mathrm{SD}$ & $7.6 \pm 7.0$ \\
\hline Modified early warning score, mean \pm SD & $4.7 \pm 2.1$ \\
\hline \multicolumn{2}{|l|}{ Reasons for activation, $\mathrm{n}(\%)$} \\
\hline 1. Low $\mathrm{BP}(\mathrm{SBP}<90 \mathrm{mmHg})$ & $15(25.9)$ \\
\hline 2. $\mathrm{HR}(<50 / \mathrm{min},>140 / \mathrm{min}$, or symptomatic arrhythmia $)$ & $10(17.2)$ \\
\hline 3. $\mathrm{RR}(<10 / \mathrm{min},>30 / \mathrm{min}$, accessory muscle use, or stridor $)$ & $13(22.4)$ \\
\hline 4. $\mathrm{BT}\left(>39^{\circ} \mathrm{C}\right.$ or $\left.<36^{\circ} \mathrm{C}\right)$ & $2(3.4)$ \\
\hline 5. Pain: chest pain suggesting angina & $0(0)$ \\
\hline 6. Neurology & $0(0)$ \\
\hline 7. Oxygenation $\left(\mathrm{SaO}_{2}<90 \%\right.$ in room air or $\left.\mathrm{FM}>\mathrm{O}_{2} 8 \mathrm{~L} / \mathrm{min}\right)$ & $23(39.7)$ \\
\hline 8. ABGA abnormality: $\mathrm{PaCO}_{2}>50 \mathrm{mmHg}, \mathrm{pH}<7.3$, or $\mathrm{PaO}_{2}<60 \mathrm{mmHg}$ & $2(3.4)$ \\
\hline 9. Metabolic acidosis: lactic acid $>2.5 \mathrm{mmol} / \mathrm{L}, \mathrm{TCO}_{2}<15 \mathrm{mmol} / \mathrm{L}$ & $0(0)$ \\
\hline 10. Any serious concerns about overall deterioration & $1(1.7)$ \\
\hline \multicolumn{2}{|l|}{ Recommendation, $\mathrm{n}(\%)$} \\
\hline A: ICU admission & $26(44.8)$ \\
\hline $\mathrm{B}^{*}$ : Borderline intervention & $21(36.2)$ \\
\hline $\mathrm{C}^{\dagger}$ : Consultation only & $4(6.9)$ \\
\hline $\mathrm{D}^{\ddagger}$ : Do not resuscitate & $7(12.1)$ \\
\hline Survival rate, $\mathrm{n}(\%)$ & $37(63.8)$ \\
\hline LOS in hospital, mean $\pm \mathrm{SD}$ & $28.9 \pm 20.5$ \\
\hline
\end{tabular}

*volume replacement (11), use antibiotics, order laboratory and radiologic exams (8), adequate oxygen supply (4), emergency embolization for bleeding (2), recommend esophagoduodenoscopy (1), use medication for HR control (1), apply noninvasive ventilation (1). ${ }^{\dagger}$ problems solved in accounting department (2), do not resuscitate was not described in the emergency medical records (1), transient change due to analgesics (1). ${ }^{\ddagger}$ Lung cancer (3), pancreatic cancer (1), extramammary Paget's disease (1), aspiration pneumonia (2). SD: standard deviation; BP: blood pressure; SBP: systolic blood pressure; HR: heart rate; RR: respiratory rate; BT: body temperature; ABGA: arterial blood gas analysis; ICU: intensive care unit; LOS: length of stay. 
ples t-tests and the $\chi^{2}$ test for continuous and categorical variables, respectively. All statistical analyses were performed with SPSS version 17.0 (IBM SPSS Statistics, Armonk, NY, USA). A two-tailed $\mathrm{p}$ value $<0.05$ was considered significant.

\section{RESULTS}

There were a total of 23,267 screened alerts during the study period. Among these lists, errors and DNRs made up approximately $45 \%$. Alert lists from surgical and medical services made up approximately $30 \%$ and $23.4 \%$ respectively. As fever is properly managed by the attending physician in the medical service, the RRS team did not usually intervene for patients for whom the RRS was activated because of fever (Fig. 2).

\section{1) RRS activations and interventions}

Among 4,849 actual alert lists (from 2,505 patients), the RRS was activated $2.3 \%$ of the time $(n=58)$. The clinical findings encountered by the RRS doctors and interventions undertaken are listed in Table 2. Most RRS activations were through automatic screening systems by EMRs, and only $16 \%$ were direct calls for help. The mean response time to RRS activation was 7.6 minutes. The most frequent screening criteria for RRS activation were low saturation and low blood pressure. Furthermore, $44.8 \%$ of patients were transferred to the MICU, and DNR was ordered in $12.1 \%$ of patients.

Among 58 cases, 26 patients were admitted to the MICU (Table 3); their mean age was 67.2 , and $70 \%$ were male. About $70 \%$ of patients were transferred from hemato-oncology and respiratory wards. The most common reason for ICU admission was respiratory failure. Survival in the ICU was $80.8 \%$, and the mean ICU length of stay was 6.2 days. Patients admitted to the MICU via the RRS and conventional method during the same period (Table 3) had comparable APACHE-II scores (24.4 vs. $25.4, \mathrm{p}=0.522)$, but the RRS group had a significantly lower SOFA score $(7.4$ vs. $8.9, \mathrm{p}=0.024)$. Moreover, the RRS group tended to have lower rates of endotracheal intubation and renal replacement therapy as well as a shorter duration of intubation, although the differences were not significant. In addition, the RRS group tended to have a higher extubation rate and improved survival in ICU, although the differences were not significant. The median length of ICU stay was significantly shorter in RRS group than the conventional group (6.2 vs. 9.9 days, $\mathrm{p}=0.018$ ).

\section{2) RRS implementation and cardiopulmonary arrest}

The non-ICU cardiopulmonary arrest rate per 1,000 hospital admissions in the medical service did not decrease after implementing the RRS (before RRS: 0.94 [0.25-2.42]; after RRS: 0.97 [0.45-2.28]; $\mathrm{p}=0.082$ ).

Table 3. Characteristics of patients with ICU admission via the RRS and conventional method

\begin{tabular}{|c|c|c|c|}
\hline & $\begin{array}{c}\text { RRS } \\
(\mathrm{n}=26)\end{array}$ & $\begin{array}{l}\text { Conventional method } \\
(\mathrm{n}=311)\end{array}$ & $\mathrm{p}$ value \\
\hline Age, mean \pm SD & $69.2 \pm 10.8$ & $68.6 \pm 15.2$ & 0.774 \\
\hline Male sex, $n(\%)$ & $18(69.2)$ & $204(65.6)$ & 0.707 \\
\hline APACHE-II score, mean \pm SD & $24.4 \pm 7.5$ & $25.4 \pm 8.7$ & 0.519 \\
\hline SOFA score, mean \pm SD & $7.4 \pm 3.3$ & $8.9 \pm 4.3$ & 0.024 \\
\hline Ward, n (\%) & & & 0.004 \\
\hline Hemato-oncology & $11(42.3)$ & $41(13.2)$ & $<0.001$ \\
\hline Pulmonology & $7(26.9)$ & $154(49.5)$ & 0.029 \\
\hline Gastroenterology & $3(11.5)$ & $17(5.5)$ & NS \\
\hline Geriatric medicine & $2(7.7)$ & $6(1.9)$ & NS \\
\hline Nephrology & $2(7.7)$ & $25(8.0)$ & NS \\
\hline Cardiology & $1(3.8)$ & $49(15.8)$ & NS \\
\hline Infection & 0 & $16(5.1)$ & NS \\
\hline Endocrinology & 0 & $2(0.6)$ & NS \\
\hline Rheumatology & 0 & $1(0.3)$ & NS \\
\hline Intubation, n (\%) & $18(69.2)$ & $251(80.7)$ & 0.161 \\
\hline Extubation, $\mathrm{n}(\%)$ & $11(61.1)$ & $121(48.2)$ & 0.193 \\
\hline Duration of intubation (d), mean $\pm \mathrm{SD}$ & $4.0 \pm 2.6$ & $4.4 \pm 5.4$ & 0.439 \\
\hline Renal replacement therapy, n (\%) & $4(15.4)$ & $75(24.1)$ & 0.313 \\
\hline Length of stay in ICU (d), mean \pm SD & $6.2 \pm 6.4$ & $9.9 \pm 10.4$ & 0.018 \\
\hline Survival in ICU, $\mathrm{n}(\%)$ & $20(80.8)$ & $220(71.0)$ & 0.286 \\
\hline
\end{tabular}

ICU: intensive care unit; RRS: rapid response system; SD: standard deviation; APACHE: Acute Physiology and Chronic Health Evaluation; SOFA: Sequential Organ Failure Assessment. 


\section{DISCUSSION}

To assess the activity and outcomes of an EMR-based RRS for hospitalized patients in internal services, we analyzed 4,849 alert lists generated from 2,505 patients; the RRS was activated in 58 cases including 26 patients (44.8\%) admitted to the ICU. DNR was initiated by the RRS physician in $12.1 \%$ of cases. ICU admission via the RRS resulted in a significantly shorter length of stay in the ICU than that with conventional admission.

A previous study analyzed cases of cardiopulmonary arrest and found that $25 \%$ of attending nurses did not call doctors when encountering abnormal vital signs and junior doctors did not report to senior doctors $43 \%$ of the time.[11] Easy access and active use of the RRS are important for successful implementation. Therefore, we adopted an active screening system based on EMRs rather than merely waiting for calls. Our monitoring system detects at-risk patients according to predefined criteria immediately after their data are entered into the EMR system. However, cases of high emergency, wherein there is no time to input the abnormal vital signs into the EMR system, would be lost, thereby yielding unexpected results. Therefore, ward nurses should be instructed to alert the RRS in high emergency situations.

Our RRS based on EMR screening with predefined criteria demonstrated a shorter length of stay in the ICU compared to conventional ICU admission. Research on strategies for improving quality and reducing costs by changing the way care is provided to critically ill patients have recently focused on assessing patients with a prolonged length of stay in the ICU.[12-14] Prolonged ICU stay can adversely affect health status by increasing the risks of infection, complications, and even mortality.[15] In addition, ICU length of stay has been used as a surrogate measure of resource utilization in the ICU.[13,16-18] Therefore, we expect the RRS to improve the bed turnover rate in the ICU as a long-term outcome.

In the present study, patients with ICU admission via the RRS tended to have better clinical outcomes (i.e., mortality, duration of intubation, rate of intubation, extubation, and renal replacement therapy) compared to conventional admission. Although patients admitted via the RRS and conventional methods had similar APACHE-II scores, which represents disease severity, patients admitted via the RRS had slightly lower SOFA scores, which represents organ failure. This finding suggests that the early detection of at-risk patients in general wards and early intervention via the RRS can prevent the development of organ failure. These rapid sequences might lead to a short length of stay in the ICU as well as possible improved clinical outcomes in long-term observation.

Most studies report that the use of an RRS is associated with lower rates of cardiac arrest.[19,20] In our hospital, the total number of unexpected arrests (in all cases including medical and surgical services) likely decreased (data not shown) but not among the cases confined to the medical service. A major barrier encountered in the early phase of implementing the RRS in the medical service was a lack of support from attending physicians. Different opinions about a given situation between RRS doctors and resident physicians could lead to passive decisions. These tense relations could impede robust activity, thus affecting the outcome of the RRS and delaying its successful implementation early on. The positive support and trust of attending physicians are essential for successfully implementing the RRS.

The present study has some limitations. First, this was a single-center retrospective analysis. As these findings reflect the experience of a single tertiary referral teaching hospital, they may not be generalizable to non-teaching or low-acuity hospitals. Second, the rate of RRS activation was low, and the study was likely underpowered for some outcomes. Third, as this study analyzed patients in medical services, a selection bias may be present.

In conclusion, the present study demonstrates that RRS can be successfully implemented in medical services. ICU admission via the RRS resulted in a shorter length of ICU stay than that with conventional admission. Nevertheless, further study is required to determine long-term outcomes.

\section{Acknowledgments}

Financial/nonfinancial disclosures: The authors report that no potential conflicts of interest exist with any companies/organizations whose products or services may be discussed in this article.

\section{REFERENCES}

1) Schein RM, Hazday N, Pena M, Ruben BH, Sprung CL: Clinical antecedents to in-hospital cardiopulmonary arrest. Chest 1990; 98: 1388-92.

2) Kause J, Smith G, Prytherch D, Parr M, Flabouris A, Hillman $\mathrm{K}$ : A comparison of antecedents to cardiac arrests, deaths and emergency intensive care admissions in Australia and New Zealand, and the United Kingdom--the ACADEMIA 
study. Resuscitation 2004; 62: 275-82.

3) Steel AC, Reynolds SF: The growth of rapid response systems. Jt Comm J Qual Patient Saf 2008; 34: 489-95.

4) Devita MA, Bellomo R, Hillman K, Kellum J, Rotondi A, Teres D, et al.: Findings of the first consensus conference on medical emergency teams. Crit Care Med 2006; 34: 2463-78.

5) Chan PS, Jain R, Nallmothu BK, Berg RA, Sasson C: Rapid Response Teams: A Systematic Review and Meta-analysis. Arch Intern Med 2010; 170: 18-26.

6) Young MP, Gooder VJ, McBride K, James B, Fisher ES: Inpatient transfers to the intensive care unit: delays are associated with increased mortality and morbidity. J Gen Intern Med 2003; 18: 77-83.

7) Goldhill DR, Sumner A: Outcome of intensive care patients in a group of British intensive care units. Crit Care Med 1998; 26: 1337-45.

8) McGloin H, Adam SK, Singer M: Unexpected deaths and referrals to intensive care of patients on general wards. Are some cases potentially avoidable? J R Coll Physicians Lond 1999; 33: 255-9.

9) Escarce JJ, Kelley MA: Admission source to the medical intensive care unit predicts hospital death independent of APACHE II score. JAMA 1990; 264: 2389-94.

10) Randy S. Wax: Key elements of an RRS. In: Designing, implementing, and enhancing a rapid response system. Edited by Frank Sebat: Society of Critical Care Medicine. 2009, pp31-40.

11) Franklin C, Mathew J: Developing strategies to prevent inhospital cardiac arrest: analyzing responses of physicians and nurses in the hours before the event. Crit Care Med 1994; 22: 244-7.

12) Weissman $C$ : Analyzing intensive care unit length of stay da- ta: problems and possible solutions. Crit Care Med 1997; 25: 1594-600.

13) Wong DT, Gomez M, McGuire GP, Kavanagh B: Utilization of intensive care unit days in a Canadian medical-surgical intensive care unit. Crit Care Med 1999; 27: 1319-24.

14) Miller RS, Patton M, Graham RM, Hollins D: Outcomes of trauma patients who survive prolonged lengths of stay in the intensive care unit. J Trauma 2000; 48: 229-34.

15) Gilio AE, Stape A, Pereira CR, Cardoso MF, Silva CV, Troster EJ: Risk factors for nosocomial infections in a critically ill pediatric population: a 25-month prospective cohort study. Infect Control Hosp Epidemiol 2000; 21: 340-2.

16) Knaus WA, Wagner DP, Zimmerman JE, Draper EA: Variations in mortality and length of stay in intensive care units. Ann Intern Med 1993; 118: 753-61.

17) Rapoport J, Teres D, Lemeshow S, Gehlbach S: A method for assessing the clinical performance and cost-effectiveness of intensive care units: a multicenter inception cohort study. Crit Care Med 1994; 22: 1385-91.

18) Eagle KA, Mulley AG, Skates SJ, Reder VA, Nicholson BW, Sexton JO, et al.: Length of stay in the intensive care unit. Effects of practice guidelines and feedback. JAMA 1990; 264: 992-7.

19) Bellomo R, Goldsmith D, Uchino S, Buckmaster J, Hart G, Opdam H, et al.: Prospective controlled trial of effect of medical emergency team on postoperative morbidity and mortality rates. Crit Care Med 2004; 32: 916-21.

20) Dacey MJ, Mirza ER, Wilcox V, Doherty M, Mello J, Boyer A, et al.: The effect of a rapid response team on major clinical outcome measures in a community hospital. Crit Care Med 2007; 35: 2076-82. 